\title{
America's experiment with motor vehicle safety regulation
}

\section{Strong beginnings}

Nearly three decades ago the National Motor Vehicle Safety Act of 1966 was launched by a Congress and a President who seemed determined to make American motorists safer. The legislation was passed without a dissenting vote in either the House or the Senate. It was signed by a President who had not had the temerity to request a bill as strong as the one that ultimately was sent to the White House.

The National Motor Vehicle Safety Act was politically popular, in part, because it had strong scientific and ideological foundations. The statute's scientific underpinnings borrowed from both the epidemiology of accidents and aircraft safety engineering. The most important idea was to prevent injuries and deaths by intervening between vehicle collisions and the transference of the energy of the collision to occupants. While crash avoidance was not ignored, the real payoffs from forcing automotive technology through regulation were thought to lie in the direction of preventing the so-called 'second collision' between automobile occupants and either the interior of the vehicle or external objects.

Ideologically vehicle safety regulation was supported by belief both in the efficacy of technology and the desirability of equal access to safe vehicles. In some sense the National Motor Vehicle Safety Act combined the symbolism of the space program and the civil rights movement. It insisted that the greater safety already engineered into more expensive vehicles be made available to the general populace. And, for a country that had recently landed men on the moon, this egalitarian initiative seemed to hold modest technological challenges.

\section{Reality rears its ugly head}

At the time that the Congress set the National Highway Traffic Safety Administration the task of remaking the motor vehicle by regulatory command, few asked hard questions about the feasibility of this particular public health crusade. The public record reflects little consideration of whether Americans really viewed motor vehicles primarily as a public health hazard, rather than as a mode of private self expression, and individual freedom. It was assumed that engineering was a scientific discipline and consequently that changes in motor vehicle design to promote public safety presented a relatively straightforward task. Although automobile manufacturers resisted the new legislation, it was presumed that once legislation was passed, the largest manufacturing industry in the US could be set off in a direction substantially different from the one that it had chosen and that had been validated by its enormous market success. Perhaps most importantly, it was assumed that a new health and safety regulatory agency could issue prescriptive rules expeditiously in the American legal culture - a legal culture devoted to checks and balances, to multiple opportunities for pluralistic participation in legal decision making, and to adversarial challenges to governmental authority in the courts.

Serious reflection on any of these questions might have led to sober second thoughts about the potential efficacy of motor vehicle safety regulation. At the very least, they would have promoted a sense of the difficulty of the task and might have moderated the expectations enunciated in the mid to late 1960 s.

In the ensuing three decades Americans have learned some hard lessons about reforming or redesigning the motor vehicle through command and control regulation. They have learned that technological advance is relatively slow to mature, involves much trial and error, and is hard to force by ordering levels of safety performance beyond the current 'state of the art'. They have learned that political tides can turn quickly when an industry that employs one in six Americans falls on hard times and seems to require regulatory relief rather than the increased imposition of regulatory costs. They have learned just how strong the legal barriers to action forcing regulation can be when a powerful and resourceful industry begins to pull the multitude of levers that may slow or thwart regulatory action in the American legal and political system. And American regulators, if no one else, have learned how fickle a populace can be when it learns that the safety that it demanded might require that it pay a bit extra for its shiny new toys or suffer the most modest inconvenience in operating them.

\section{Ironies and instructions}

The difficulties with reconstructing the automobile through regulation have not wholly defeated the great expectations of 1966. Some regulations have been adopted and motor vehicles are safer now than they were before. How much of this safety is due to regulatory technology forcing and how much would have occurred in the natural evolution of the vehicle is difficult to estimate. The ambiguous status of the regulatory product contrasts starkly with new understandings of the regulatory process. The clear message is that regulatory technology forcing is a very difficult and time consuming business. Moreover, the torpidity and limited effectiveness of the process are only modestly affected by the political preferences of alternating administrations and changeable Congresses. The difficulties are structural, not 'political' in the usual sense of that term.

Ironically, while regulation through rule making has proved extraordinarily difficult, recalling automobiles thought to have defects related to automobile safety has proved both easy and politically popular. Indeed, one can find five year periods over the last three decades in which more vehicles were recalled for defects in the US than were sold new. The irony in this is not just that the recall aspects of the legislation were thought relatively unimportant when the statute was passed, but that recall activity, however politically popular, has virtually no impact on the overall safety of the population at risk for motor vehicle injury or death. No systematic study of vehicle accidents and injuries has ever attributed more than $3-5 \%$ of them to design or manufacturing defects. Recalls thus operate on a vanishingly small proportion of the vehicle safety problem.

Finally, although the story of American motor vehicle safety regulation is a story of great expectations, dashed hopes, and modest accomplishments, it is far from obvious that alternative approaches would have been efficacious. Alternative techniques - information campaigns, liability insurance reform, research and development subsidies, and 
so on - all have decisive disadvantages. Moreover, a regulatory approach that has been intensely frustrating in the US might well work substantially better in countries with different legal cultures and structural arrangements. In short, the lessons of the American experience with automobile safety regulation should not be overlearned. Exploring what should be learned, however, requires detailed analysis that goes much beyond the space available in this annotation. For a more extended discussion of these and other issues the reader is referred to Jerry L Mashaw and David Harfst, The Struggle for Auto Safety (Harvard University Press, 1990).

JERRY L MASHAW

Sterling Professor of Law,

Yale Law School,

127 Wall Street,

Yale Station,

New Haven,

CT 06520, USA

\section{Injury prevention: an uphill battle}

Injuries are the most common cause of death in the first four decades of life and reduce life expectancy almost as much as diseases predominantly affecting older people, such as cancer and coronary heart disease. ${ }^{1}$ In the USA during 1992, deaths from injuries outnumbered those from AIDS by more than four to one, ${ }^{2}$ those from air pollution by more than five to one, ${ }^{3}$ and those from passive smoking by more than 100 to one. ${ }^{4}$ By virtually any criterion, therefore, injuries should represent a leading public health priority. ${ }^{56}$ Yet, research efforts and community mobilization aiming at injury prevention fade in comparison to those targeting AIDS, air pollution, or environmental tobacco smoke. This is a paradox that must be recognized, explained, and rectified if control of the injury epidemic is to have a reasonable chance of success. The critical question is: Why has injury prevention failed to generate the enthusiasm and marshal the community support that other public health issues have achieved?

People can be easily energized when they believe that a problem can be rapidly and completely resolved. Governments, public health professionals, institutions, and individual scientists are fighting AIDS in the belief that a breakthrough will sooner or later eliminate the problem. Molecular aspects of carcinogenesis have attracted some of the best scientific minds around the world struggling to resolve once and for all the mystery of cancer. The hopes of the scientists working in the fields of AIDS and cancer, as well as those of lay people, are not unreasonable. Following important discoveries, immense health problems have suddenly become milestones in the history of medicine; several infectious diseases, some conditions of occupational origin, and numerous nutritional deficiency disorders, represent striking examples of science in complete triumph. But the fight to prevent injuries and control their consequences presents no such hope for a sudden, complete victory. Reduction in the frequency of occurrence of injuries or control of their impact depends little on intellectual vision and scientific breakthroughs. They depend on incremental progress, contributed to by a vast group of health and other professionals committed to a remote and elusive objective. Prevention of injuries requires the successful convergence of efforts made by medical doctors, public health nurses, social scientists, teachers, health educators, legislators, law enforcement officers, and many others. Their task is rarely glamorous and their work is not surrounded by the aura of scientific excitement associated with studies addressing many other health problems.

What then needs to be done in the area of injury prevention? All of us working in the field realize that even though the problem we are confronting is as serious as any, injury prevention has not received the academic recognition and the research support that is urgently required. We should change that attitude by fostering attention to excellent research currently undertaken in the biological, behavioral, and other aspects of injury prevention. We should disseminate the basic concept that injuries have causes and are therefore preventable, despite the fact that the multitude of the causes and their complex nature makes prevention daunting. ${ }^{5}$ We must try to develop an interdisciplinary infrastructure, to create informative databases, and launch far reaching research undertakings. ${ }^{7-9}$ Finally, we should remind ourselves as well as policy makers, that although there is a hope for ultimate biotechnological victory in the fields of AIDS, cancer, or cardiovascular diseases-one that depends on molecular research-most of the actual progress that has been achieved in these areas has been accomplished through measures similar to those needed for the control of the injury epidemic. These measures require visionary health leadership, wide community participation, and research on injury prevention and control undertaken in a variety of fields and involving a broad spectrum of health professionals.

Injuries affect all ages, but in most of us they invoke images of despair brought about by the accidents affecting the young. The tragedy of these accidents is epitomized by the contrast of youth and happiness shattered by events that could have been anticipated and prevented. Effective injury prevention among the young can prolong life expectancy more than the successful treatment of cancer or cardiovascular diseases of the adult: it can improve the population weighted quality of life more than any intervention focusing on nutritional and other aspects of personal behavior; can form the core of additional injury prevention activities throughout our life span; and can relieve our lives of the nightmare brought about by the violation of youthful life and hope through violence and death.

E PETRIDOU

Department of Epidemiology,

Athens University Medical School,

75 M Asias Street,

Athens 11527,

Greece

1 World Health Organization. World health statistics annual 1992. Geneva: WHO, 1993.

2 Mann JM, Tarantola DJ, Netter TW, eds. Aids in the world. A global report. Cambridge, UK: Harvard University Press, 1992; 1038.

3 Lippmann M. ed. Environmental toxicants. Human exposures and their health effects. New York: Van Nostrand Reinhold, 1992; 699.

4 Tricholpoulos $D$. Risk of cancer from passive smoking. Principles and Practice of Oncology: PPO Updates 1994; 8: 1-8.

5 The National Committee for Injury Prevention and Control. Injury prevention: meeting the challenge. New York, NY: Oxford University Press. Am I Prev Med 1989; 5 (suppl): 305.

6 Department of Health. The health of the nation: a strategy for health in England. London: HMSO, 1992.

7 Shelov SP. The children's agenda for the 1990's and beyond. Am f Public Health 1994; 84: 1066-7.

8 Centers for Disease Control. Report from the 1988 trauma registry workshop, including recommendations for hosptal based trauma registries. I Trauma 1989; 29: 827-34.

9 Petridou E, Nakou S, eds. Research agenda towards developing a policy for injury prevention among young people in Greece with emphasis on consumer
products. Proceedings of conference. Center for Research and Prevention of Health Promotion. Athens, 1994: 154. 